\title{
Extraction of proanthocyanidins from grape seeds and their protective effect on spinal cord injury in rats
}

\author{
Yunzhong ZHAN ${ }^{1 *}$ (D), Fan YANG², Zhou YE ${ }^{1}$, Junchao ZHANG ${ }^{1}$, Yi MAOํ․ Lei LI ${ }^{1}$
}

\begin{abstract}
Proanthocyanidins were extracted and purified from grape seeds, and the protective effect and mechanism of proanthocyanidins on spinal cord injury were explored. After extraction optimization and purification, the proanthocyanidins with purity of $92.53 \%$ were obtained. The rats were divided into control, model and treatment groups. The spinal cord injury model was established in model and treatment groups. Then, the treatment group was treated with $40 \mathrm{mg} / \mathrm{kg}$ proanthocyanidins. On the $1 \mathrm{st}$, 3rd and 7th day after modeling, compared with model group, in model group the Basso-Beattie-Bresnahan scores were significantly decreased $(\mathrm{p}<0.05)$. On the 7th day after modeling, compared with model group, in treatment group the spinal cord tissue superoxide dismutaseand glutathione peroxidase levels were significantly increased $(p<0.05)$, the malondialdehyde level was

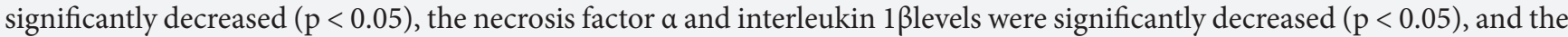
interleukin 10 level was significantly increased $(\mathrm{p}<0.05)$. In conclusion, proanthocyanidins have protective effect on spinal cord injury in rats. The mechanisms may be related to its reducing oxidative stress and inflammation in spinal cord tissue.
\end{abstract}

Keywords: proanthocyanidins; spinal cord injury; rats; oxidative stress; inflammation.

Practical Application: Proanthocyanidins are applied to protect against spinal cord injury in rats.

\section{Introduction}

Spinal cord injury is often caused by the spine burst or displacement due to different ways of external force. It is one of the most common severe diseases in clinic. In recent years, with the development of industry, construction, sports and transportation, the incidence of spinal cord injury is increasing (Miyakoshi et al., 2021). Spinal cord injury can be divided into two stages including primary injury and secondary injury. Studies have shown that the secondary spinal cord injury may lead to the further neurodegenerative diseases (Austin \& Fehlings, 2008; López-Serrano et al., 2016). It has been found that the oxidative stress and inflammation play an important role in spinal cord injury (Zhaohui \& Shuihua, 2020; Guan \& Wang, 2021). Therefore, how to reduce the oxidative stress and inflammation is the focus of clinical treatment of spinal cord injury.

Proanthocyanidins are a class of active phenolic compounds mainly existing in grape seeds and grape skins. In recent years, scholars have done a lot of research on the physical and chemical properties and biological characteristics of proanthocyanidins. They find that, proanthocyanidins have the strong effect in resisting oxidative stress (Chen L et al., 2020), reducing apoptosis (Mantena et al., 2006), regulating immunity (Williams et al., 2016), and preventing cancer (Chen et al., 2014). In addition, they have the characteristics of high efficiency, low toxicity and high bioavailability (Choy et al., 2013). It is found that proanthocyanidins can enhance the stability of the nervous system (Moreira et al., 2010). However, whether proanthocyanidins have protective effect on spinal cord injury has not been reported. In this study, proanthocyanidins were extracted from grape seeds, and the extraction technologies were investigated. Then, the rat model of spinal cord injury was established, and the protective effect and mechanism of proanthocyanidins on spinal cord injury were explored.

\section{Materials and methods}

\subsection{Extraction of proanthocyanidins from grape seeds}

A $500 \mathrm{~g}$ of petroleum ether-degreased grape seed powder was added to the extraction kettle, and then the ethanol solution was added. The extraction was performed under different ethanol concentration, solid-liquid ratio, extraction temperature and extraction time. Finally, the extraction solution was filtered. The filtrate was concentrated by rotary evaporation, followed by freeze-drying. The crude proanthocyanidins product was obtained. After weighing, the content of proanthocyanidins in product was determined. The extraction yield was calculated.

\subsection{Purification of crude proanthocyanidins product}

The crude proanthocyanidins product was dissolved with water to a concentration of $50 \mathrm{mg} / \mathrm{ml}$, and then was added to the pretreated AB-8 macroporous adsorption resin column. The gradient elution was performed using $20-80 \%$ ethanol solution. The target elution solution was collected, followed by concentration under 
reduced pressure and freeze-drying. The products were loaded to the Sephadex LH-20 gel chromatography column, followed by gradient elution using $20-100 \%$ ethanol solution. The target elution solution was collected. After concentration under reduced pressure and freeze-drying, the final proanthocyanidins product was obtained. After weighing, the content of proanthocyanidins in final product was determined.

\subsection{Establishment of spinal cord injury model}

Thirty SPF-grade male SD rats (250-300 g) were divided into control, model and treatment groups, with 10 rats in each group. In model and treatment groups, the rats were anesthetized by intraperitoneal injection of $10 \%$ chloral hydrate, and were fixed in prone position. A $3 \mathrm{~cm}$ longitudinal incision was made in the posterior midline of back to expose the paravertebral muscles. The T10 lamina, spinous process and transverse process were exposed by blunt dissection of muscles. The spinal canal was expanded to expose the spinal cord, keeping the dura mater intact. The T10 spinal cord was struck with a $60 \mathrm{~g} \cdot \mathrm{cm}$ impactor $(10 \mathrm{~g}$ metal rod falling from $6 \mathrm{~cm}$ height). After staying for $3 \mathrm{~min}$, the metal rod was removed. The success criteria for establishment of SCI model were as follows: the dura mater presented purple; there were swelling, edema and hemorrhage in spinal cord; the rats presented spasmodic shaking of both lower extremities and spasmodic swing of tail. In control group, only T10 spinal cord was exposed, without striking, the other surgical operations were the same with other two groups. During the modeling, one and two rats died in model and treatment groups, respectively. After surgery, penicillin (80000 U/day) was injected intramuscularly for three days. The bladder massage was performed to assist the urination.

\subsection{Treatment methods}

Immediately after modeling, the treatment group was intraperitoneally injected with $40 \mathrm{mg} / \mathrm{kg}$ proanthocyanidins. The control and model groups were synchronously intraperitoneally injected with equal volume of normal saline. The treatment was performed once a day, for seven days.

\subsection{Basso-Beattie-Bresnahan (BBB) behavioral scoring}

On the 1st, 3rd and 7th day after modeling, the hind limb motor function of rats in each group was evaluated using BBB scores by double-blind method (Basso et al., 1995). The score of 0 point and 21 points represented total paralysis and normal motor function, respectively.

\subsection{Biochemical index detection}

On the 7th day after modeling, the rats were sacrificed under anesthesia. The injured spinal cord tissue was obtained and the homogenate was made. After centrifuging at $3000 \mathrm{r} / \mathrm{min}$ and $-10{ }^{\circ} \mathrm{C}$ for $20 \mathrm{~min}$, the supernatant was obtained. The protein content was determined by Coomassie brilliant blue method. The oxidative stress indexes including superoxide dismutase (SOD) activity and glutathione peroxidase (GSH-Px) activities and malondialdehyde (MDA) content were measured using the corresponding kits. The inflammatory factors including necrosis factor $\alpha$ (TNF- $\alpha$ ), interleukin (IL)-1 $\beta$ and IL-10 were detected using enzyme-linked immunosorbent assays.

\subsection{Statistical analysis}

The statistical analysis was performed using SPSS 18.0 software. Data were presented as mean $\pm \mathrm{SD}$. The comparison of data among three groups was conducted using single-factor analysis of variance test with SNK-q test. A p-value of $<0.05$ (2-tailed) was considered as statistically significant.

\section{Results}

\subsection{Extraction and purification results}

The optimization experiments showed that, the optimal extraction conditions of proanthocyanidins from grape seeds were as follows: ethanol solution concentration, $60 \%$; solid-liquid ratio, 1:4 (g: $\mathrm{ml}$ ), extraction time, $90 \mathrm{~min}$; extraction temperature, $75^{\circ} \mathrm{C}$. Under these conditions, the yield of proanthocyanidins was $10.2 \%$. After purification using AB-8 macroporous resin column and Sephadex LH-20 gel chromatography column, the content of proanthocyanidins in the final product was $92.53 \%$.

\subsection{General condition of rats}

After striking of spinal cord, the rats in control group presented normal condition. In model group, the rats presented typical spasmodic shaking of both lower extremities and spasmodic swing of tail. After recovery from anesthesia, the both lower extremities suffered from flaccid paralysis, and the urine retention and urinary incontinence occurred. From three days after modeling, partial rats began to have a small amount of activities, less food intake, and severe urinary retention. Since then, the diet and activities gradually increased. In treatment group, the symptoms were basically the same with model, but the degree was obviously reduced. After bladder massage, all rats were able to urinate autonomously.

\subsection{Effect of proanthocyanidins on BBB scores of rats with spinal cord injury}

From the 1st day to the 7th day after modeling, the BBB scores of in three groups gradually increased. At each time point, the BBB scores in model and treatment groups were significantly lower than those in control group, respectively $(\mathrm{p}<0.05)$. Compared with model group, the BBB scores in treatment group at each time point were significantly decreased $(p<0.05)$ (Figure 1$)$.

\subsection{Effect of proanthocyanidins on spinal cord tissue SOD, GSH-Px and MDA levels in rats with spinal cord injury}

As shown in Figure 2, on the 7th day after modeling, compared with control group, in model and treatment groups the spinal cord tissue SOD and GSH-Px levels were significantly decreased, respectively $(\mathrm{p}<0.05)$, and the MDA level was significantly increased, respectively $(\mathrm{p}<0.05)$. Compared with model group, in treatment group the SOD and GSH-Px levels 


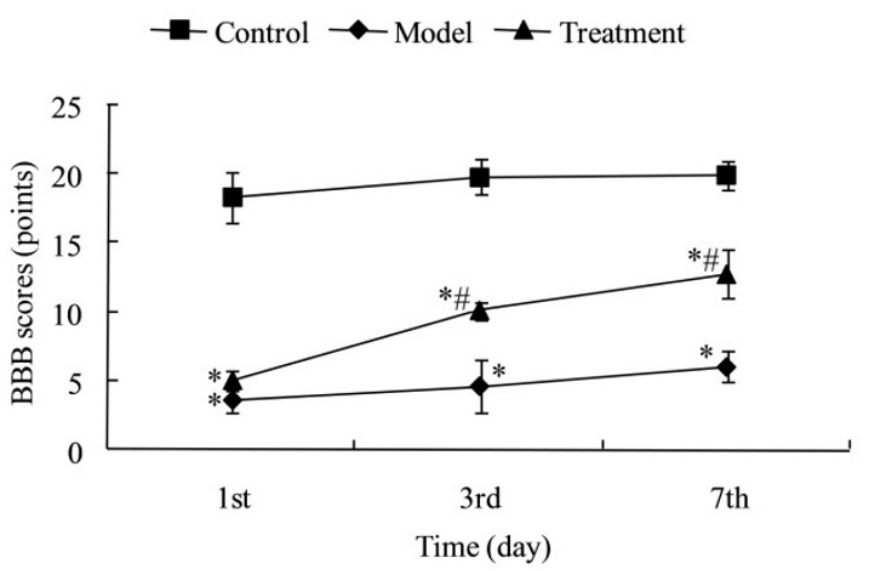

Figure 1. Comparison of $\mathrm{BBB}$ scores among three groups. Control: $\mathrm{n}=10$; model: $\mathrm{n}=9$; treatment: $\mathrm{n}=8 ; 1$ st day: $\mathrm{F}=364.691, \mathrm{p}<0.001 ; 3$ rd day: $\mathrm{F}=313.741, \mathrm{p}<0.001 ; 7$ th day: $\mathrm{F}=255.884, \mathrm{p}<0.001 ;{ }^{*} \mathrm{p}<0.05$ vs. control group; ${ }^{*} \mathrm{p}<0.05$ vs. model group; BBB: Basso-Beattie-Bresnahan. were significantly increased, respectively $(p<0.05)$, and the MDA level was significantly decreased $(\mathrm{p}<0.05)$.

\subsection{Effect of proanthocyanidins on spinal cord tissue TNF- $\alpha$, $I L-1 \beta$ and $I L-10$ levels in rats with spinal cord injury}

On the 7 th day after modeling, the spinal cord tissue TNF- $\alpha$ and IL-1 $\beta$ levels in model and treatment groups were significantly higher than those in control group, respectively $(\mathrm{p}<0.05)$, and the IL-10 level in model and treatment groups was significantly lower than that in control group ( $\mathrm{p}<0.05)$. Compared with model group, in treatment group the TNF- $\alpha$ and IL- $1 \beta$ levels were significantly decreased, respectively $(\mathrm{p}<0.05)$, and the IL-10 level was significantly increased $(\mathrm{p}<0.05)$ (Figure 3$)$.

\section{Discussion}

Proanthocyanidins are internationally recognized as one of the most effective natural antioxidants. Studies have found
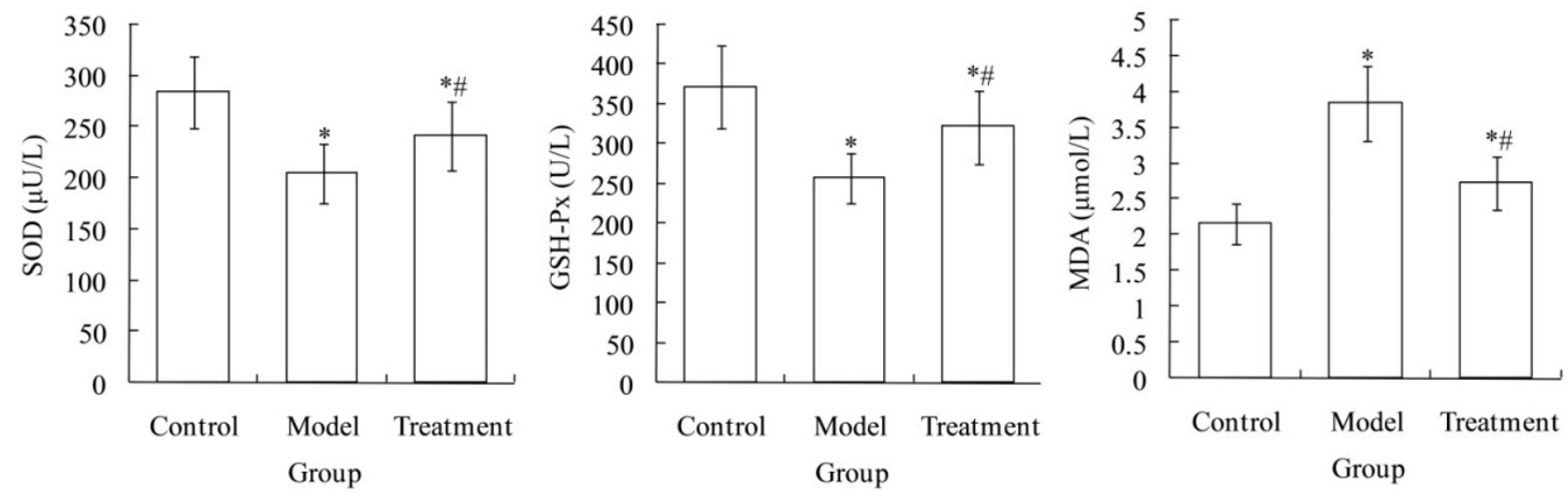

Figure 2. Comparison of spinal cord tissue SOD, GSH-Px and MDA levels among three groups. Control: $\mathrm{n}=10 ; \mathrm{model}: \mathrm{n}=9$; treatment: $\mathrm{n}=8$; SOD: $\mathrm{F}=14.083, \mathrm{p}<0.001$; GSH-Px: $\mathrm{F}=41.980, \mathrm{p}<0.001$; MDA: $\mathrm{F}=15.573, \mathrm{p}<0.001 ;{ }^{*} \mathrm{p}<0.05$ vs. control group; ${ }^{*} \mathrm{p}<0.05$ vs. model group; SOD: superoxide dismutase; GSH-Px: glutathione peroxidase; MDA: malondialdehyde.
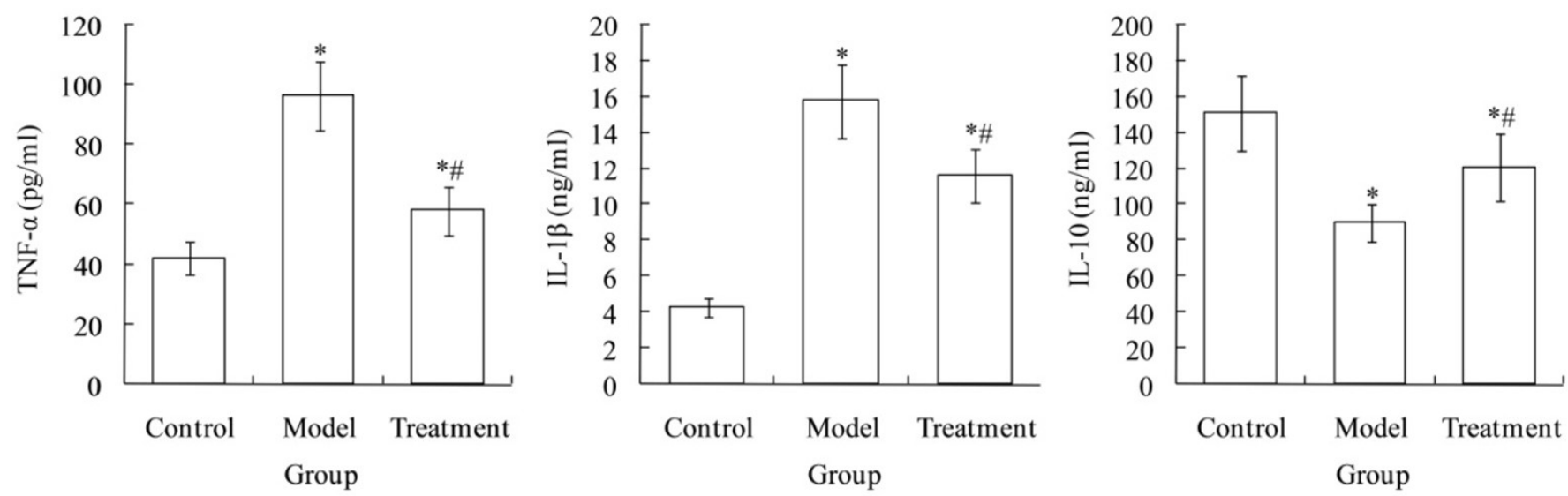

Figure 3. Comparison of spinal cord tissue TNF- $\alpha$, IL-1 $\beta$ and IL-10 levels among three groups. Control: $n=10 ;$ model: $n=9$; treatment: $n=8$; TNF- $\alpha$ : $F=94.820, p<0.001 ;$ IL-1 $\beta: F=151.406, p<0.001 ;$ IL-10: $\mathrm{F}=29.541, \mathrm{p}<0.001 ;{ }^{*} \mathrm{p}<0.05$ vs. control group; ${ }^{*} \mathrm{p}<0.05$ vs. model group; TNF- $\alpha$, necrosis factor $\alpha$; IL- $1 \beta$, interleukin $1 \beta$; IL-10, interleukin 10. 
that proanthocyanidins from grape seed has many biological functions, such as anti-oxidation, anti-inflammation, anti-tumor, anti-radiation, anti-obesity, reducing blood lipid and protecting cardiovascular system (Rauf et al., 2019). They are widely used in the fields of food, pharmacy and medical care. In this study, proanthocyanidins were extracted and purified from grape seeds, and the content of proanthocyanidins in the final product was $92.53 \%$. Then, the rat model of spinal cord injury was established, and the protective effect of proanthocyanidins on spinal cord injury was explored. Results showed that, compared with model group, in treatment group, the spinal cord injury symptoms were obviously relieved, and the BBB scores were significantly decreased. This indicates that, the proanthocyanidins treatment has the protective effect on spinal cord injury in rats.

Studies have confirmed that the excess of free radicals and lipid peroxidation are the important reasons for the secondary injury of spinal cord injury. After spinal cord injury, a large number of free radicals cannot be eliminated, resulting in continuous lipid peroxidation to generate more free radicals, affecting the respiratory function of nerve cells, and eventually causing the nerve cell death (Lucas et al., 2002; Ishii et al., 2018). SOD is an enzyme that catalyzes the disproportionation of superoxide anion. It can protect cells against the damage of oxygen free radicals (Kalra et al., 1988). GSH-Px is an important enzyme which reduces toxic peroxides to non-toxic hydroxyl compounds, and promote the decomposition of $\mathrm{H}_{2} \mathrm{O}_{2}$, so as to protect the structure and function of cell membrane from the interference and damage of oxides (Kawai et al., 1988). MDA is the final product of lipid peroxidation of polyunsaturated fatty acids (Vagnozzi et al., 1999). SOD, GSH-Px and MDA are important indicators of oxidative stress. In this study, on the 7th day after modeling, compared with model group, in treatment group the spinal cord tissue SOD and GSH-Px levels were significantly increased, and the MDA level was significantly decreased. This suggests that proanthocyanidins can alleviate the spinal cord injury in rats by reducing the oxidative stress.

Inflammation is closely related to the spinal cord injury. The interaction of various pro-inflammatory and anti-inflammatory factors directly affects the prognosis of spinal cord injury (Hu et al., 2015). TNF- $\alpha$ and IL- $1 \beta$ are the pro-inflammatory factors, which are produced by activated macrophages and participate in the recruitment of inflammatory cells. TNF- $\alpha$ can reflect the severity of spinal cord injury. It can significantly decrease the expression of Caspase- 3 and caspase- 8 by inhibiting the TNF- $\alpha$ receptor, thus alleviating the apoptosis of neurons and oligodendrocytes (Chen et al., 2011). IL-1 $\beta$ is expressed in the early stage of spinal cord injury. It can stimulate the expression of TNF- $\alpha$ after spinal cord injury and activate the microglia/macrophage system, thus aggravating the damage of spinal cord and slow down the recovery of motor neuron function (Sato et al., 2012). IL-10 is a negative regulator of immune response. It can inhibit TNF- $\alpha$ after spinal cord injury, and plays the role of neuroprotection and promotion of injury repair (Bethea et al., 1999). In the present study, on the 7th day after modeling, compared with model group, in treatment group the spinal cord tissue TNF- $\alpha$ and IL- $1 \beta$ levels were significantly decreased, and the IL- 10 level was significantly increased. This indicates that, proanthocyanidins can reduce the inflammatory response, which may be related to its protective effect on spinal cord injury in rats.

\section{Conclusion}

In conclusion, proanthocyanidins are extracted from grape seeds. The optimal extraction conditions were as follows: ethanol solution concentration, $60 \%$; solid-liquid ratio, $1: 4(\mathrm{~g}: \mathrm{ml})$, extraction time, $90 \mathrm{~min}$; extraction temperature, $75^{\circ} \mathrm{C}$. Under these conditions, the yield of proanthocyanidins was $10.2 \%$. After purification, the content of proanthocyanidins in the final product is $92.53 \%$. Proanthocyanidins have protective effect on spinal cord injury in rats. The mechanisms may be related to its reducing oxidative stress and inflammation in spinal cord tissue. However, as there are many factors involving the spinal cord injury, the action mechanisms of proanthocyanidins still need to be further clarified.

\section{References}

Austin, J. W., \& Fehlings, M. G. (2008). Molecular mechanisms of Fasmediated cell death in oligodendrocytes. Journal of Neurotrauma, 25(5), 411-426. http://dx.doi.org/10.1089/neu.2007.0436. PMid:18435595.

Basso, D. M., Beattie, M. S., \& Bresnahan, J. C. (1995). A sensitive and reliable locomotor rating scale for open field testing in rats. Journal of Neurotrauma, 12(1), 1-21. http://dx.doi.org/10.1089/ neu.1995.12.1. PMid:7783230.

Bethea, J. R., Nagashima, H., Acosta, M. C., Briceno, C., Gomez, F., Marcillo, A. E., Loor, K., Green, J., \& Dietrich, W. D. (1999). Systemically administered interleukin-10 reduces tumor necrosis factor-alpha production and significantly improves functional recovery following traumatic spinal cord injury in rats. Journal of Neurotrauma, 16(10), 851-863. http://dx.doi.org/10.1089/neu.1999.16.851. PMid:10547095.

Chen, K. B., Uchida, K., Nakajima, H., Yayama, T., Hirai, T., Watanabe, S., Guerrero, A. R., Kobayashi, S., Ma, W. Y., Liu, S. Y., \& Baba, H. (2011). Tumor necrosis factor- $\alpha$ antagonist reduces apoptosis of neurons and oligodendroglia in rat spinal cord injury. Spine, 36(17), 1350-1358. http://dx.doi.org/10.1097/BRS.0b013e3181f014ec. PMid:21224756.

Chen, L., Hu, S. L., Xie, J., Yan, D. Y., Weng, S. J., Tang, J. H., Wang, B. Z., Xie, Z. J., Wu, Z. Y., \& Yang, L. (2020). Proanthocyanidinsmediated Nrf2 activation ameliorates glucocorticoid-induced oxidative stress and mitochondrial dysfunction in osteoblasts. Oxidative Medicine and Cellular Longevity, 2020, 9102012. http:// dx.doi.org/10.1155/2020/9102012. PMid:33062149.

Chen, Q., Liu, X. F., \& Zheng, P. S. (2014). Grape seed proanthocyanidins (GSPs) inhibit the growth of cervical cancer by inducing apoptosis mediated by the mitochondrial pathway. PLoS One, 9(9), e107045. http://dx.doi.org/10.1371/journal.pone.0107045. PMid:25187959.

Choy, Y. Y., Jaggers, G. K., Oteiza, P. I., \& Waterhouse, A. L. (2013). Bioavailability of intact proanthocyanidins in the rat colon after ingestion of grape seed extract. Journal of Agricultural and Food Chemistry, 61(1), 121-127. http://dx.doi.org/10.1021/jf301939e. PMid:23244439.

Guan, C., \& Wang, Y. (2021). LncRNA CASC9 attenuates lactate dehydrogenase-mediated oxidative stress and inflammation in spinal cord injury via sponging miR-383-5p. Inflammation, 44(3), 923-933. http://dx.doi.org/10.1007/s10753-020-01387-7. PMid:33438067.

Hu, J., Zeng, L., Huang, J., Wang, G., \& Lu, H. (2015). miR-126 promotes angiogenesis and attenuates inflammation after contusion spinal 
cord injury in rats. Brain Research, 1608, 191-202. http://dx.doi. org/10.1016/j.brainres.2015.02.036. PMid:25724143.

Ishii, H., Petrenko, A. B., Sasaki, M., Satoh, Y., Kamiya, Y., Tobita, T., Furutani, K., Matsuhashi, M., Kohno, T., \& Baba, H. (2018). Free radical scavenger edaravone produces robust neuroprotection in a rat model of spinal cord injury. Brain Research, 1682, 24-35. http:// dx.doi.org/10.1016/j.brainres.2017.12.035. PMid:29294349.

Kalra, J., Lautner, D., Massey, K. L., \& Prasad, K. (1988). Oxygen free radicals induced release of lysosomal enzymes in vitro. Molecular and Cellular Biochemistry, 84(2), 233-238. http://dx.doi.org/10.1007/ BF00421058. PMid:3231225.

Kawai, S., Komura, J., Asada, Y., \& Niwa, Y. (1988). Experimental burninduced changes in lipid peroxide levels, and activity of superoxide dismutase and glutathione peroxidase in skin lesions, serum, and liver of mice. Archives of Dermatological Research, 280(3), 171-175. http://dx.doi.org/10.1007/BF00456850. PMid:3377528.

López-Serrano, C., Torres-Espín, A., Hernández, J., Alvarez-Palomo, A. B., Requena, J., Gasull, X., Edel, M. J., \& Navarro, X. (2016). Effects of the post-spinal cord injury microenvironment on the differentiation capacity of human neural stem cells derived from induced pluripotent stem cells. Cell Transplantation, 25(10), 18331852. http://dx.doi.org/10.3727/096368916X691312. PMid:27075820.

Lucas, J. H., Wheeler, D. G., Guan, Z., Suntres, Z., \& Stokes, B. T. (2002). Effect of glutathione augmentation on lipid peroxidation after spinal cord injury. Journal of Neurotrauma, 19(6), 763-775. http://dx.doi. org/10.1089/08977150260139138. PMid:12165136.

Mantena, S. K., Baliga, M. S., \& Katiyar, S. K. (2006). Grape seed proanthocyanidins induce apoptosis and inhibit metastasis of highly metastatic breast carcinoma cells. Carcinogenesis, 27(8), 1682-1691. http://dx.doi.org/10.1093/carcin/bgl030. PMid:16597645.

Miyakoshi, N., Suda, K., Kudo, D., Sakai, H., Nakagawa, Y., Mikami, Y., Suzuki, S., Tokioka, T., Tokuhiro, A., Takei, H., Katoh, S., \& Shimada, Y. (2021). A nationwide survey on the incidence and characteristics of traumatic spinal cord injury in Japan in 2018.
Spinal Cord, 59(6), 626-634. http://dx.doi.org/10.1038/s41393-02000533-0. PMid:32782342.

Moreira, E. L., Rial, D., Duarte, F. S., de Carvalho, C. R., Horst, H., Pizzolatti, M. G., Prediger, R. D., \& Ribeiro-do-Valle, R. M. (2010). Central nervous system activity of the proanthocyanidin-rich fraction obtained from Croton celtidifolius in rats. The Journal of Pharmacy and Pharmacology, 62(8), 1061-1068. http://dx.doi. org/10.1111/j.2042-7158.2010.01124.x. PMid:20663041.

Rauf, A., Imran, M., Abu-Izneid, T., Iahtisham-Ul-Haq, Patel, S., Pan, X., Naz, S., Sanches Silva, A., Saeed, F., \& Rasul Suleria, H. A. (2019). Proanthocyanidins: a comprehensive review. Biomedicine and Pharmacotherapy, 116, 108999. http://dx.doi.org/10.1016/j. biopha.2019.108999. PMid:31146109.

Sato, A., Ohtaki, H., Tsumuraya, T., Song, D., Ohara, K., Asano, M., Iwakura, Y., Atsumi, T., \& Shioda, S. (2012). Interleukin-1 participates in the classical and alternative activation of microglia/macrophages after spinal cord injury. Journal of Neuroinflammation, 9(1), 65. http:// dx.doi.org/10.1186/1742-2094-9-65. PMid:22483094.

Vagnozzi, R., Marmarou, A., Tavazzi, B., Signoretti, S., Di Pierro, D., del Bolgia, F., Amorini, A. M., Fazzina, G., Sherkat, S., \& Lazzarino, G. (1999). Changes of cerebral energy metabolism and lipid peroxidation in rats leading to mitochondrial dysfunction after diffuse brain injury. Journal of Neurotrauma, 16(10), 903-913. http://dx.doi.org/10.1089/ neu.1999.16.903. PMid:10547099.

Williams, A. R., Fryganas, C., Reichwald, K., Skov, S., Mueller-Harvey, I., \& Thamsborg, S. M. (2016). Polymerization-dependent activation of porcine $\gamma \delta$ T-cells by proanthocyanidins. Research in Veterinary Science, 105, 209-215. http://dx.doi.org/10.1016/j.rvsc.2016.02.021. PMid:27033935.

Zhaohui, C., \& Shuihua, W. (2020). Protective effects of SIRT6 against inflammation, oxidative stress, and cell apoptosis in spinal cord injury. Inflammation, 43(5), 1751-1758. http://dx.doi.org/10.1007/ s10753-020-01249-2. PMid:32445068. 